\title{
El problema de las fuentes escépticas en el Renacimiento: el caso del Quod nihil scitur de Francisco Sánchez
}

\author{
The issue of the skeptical sources in the Renaissance: \\ the case of Sanchez's Quod nihil scitur
}

\author{
Manuel Bermúdez Vázquez \\ Universidad de Córdoba \\ Córdoba, España \\ E-mail:162bevam@uco.es \\ ORCID: 0000-0001-6117-2138
}

Fecha de recepción: 10 de junio de 2018 Fecha de aceptación: 27 de julio de 2018 Doi: 10.17533/10.17533/udea.ef.n60a10

Resumen. Entre las problemáticas que la investigación contemporánea ha tenido que tratar a la hora de analizar la recuperación del escepticismo en el Renacimiento, no solo se encuentra la cuestión de las fuentes que nutrieron esta vena, sino también el tipo de escepticismo que estas fuentes transmitieron. En estas páginas nos proponemos revisar la cuestión de las fuentes que influyeron en la redacción de una de las obras fundamentales del escepticismo renacentista, el Que nada se sabe del tudense Francisco Sánchez.

Palabras clave: filosofía, escepticismo, Renacimiento, Francisco Sánchez

Abstract. Among the problems that contemporary research has had to deal with when analyzing the recovery of skepticism in the Renaissance, there is not only the question of the sources, but also the type of skepticism that these sources transmitted. In these pages we propose to revisit the question of the sources that influenced the writing of one of the fundamental works of Renaissance skepticism, Francisco Sanchez's book That nothing is known.

Key words: philosophy, skepticism, Renaissance, Francisco Sánchez

* El presente trabajo es el resultado de la investigación desarrollada en el marco del proyecto $\mathrm{I}+\mathrm{D}+\mathrm{i}$ "El escepticismo pirrónico-empírico y el escepticismo académico en su desarrollo histórico: escepticismo y heterodoxia en la filosofía medieval y en el Renacimiento", financiado por el Ministerio de Educación y Ciencia del Gobierno de España. Universidad de Córdoba.

Cómo citar este artículo:

MLA: Bermúdez Vázquez, Manuel. "El problema de las fuentes escépticas en el Renacimiento: el caso del Quod nihil scitur de Francisco Sánchez”. Estudios de Filosofia 60 (2019): 203-215.

APA: Bermúdez Vázquez, M. (2019). El problema de las fuentes escépticas en el Renacimiento: el caso del Quod nihil scitur de Francisco Sánchez. Estudios de Filosofia, 60, 203-215.

Chicago: Manuel Bermúdez Vázquez. "El problema de las fuentes escépticas en el Renacimiento: el caso del Quod nihil scitur de Francisco Sánchez”. Estudios de Filosofia n. ${ }^{\circ} 60$ (2019): 203-215. 
El problema de la interpretación de la filosofía de Francisco Sánchez el escéptico (1551-1623) está estrechamente vinculado con el problema de la individualización de las fuentes que influyeron en su escepticismo y, por ende, en el escepticismo del Renacimiento en general. Esta discusión ya la hemos traído a colación en diversas ocasiones en las que nos hemos aproximado a la obra filosófica de este autor tudense (Bermúdez, 2006; 2014). No obstante, la cuestión de las fuentes del escepticismo de Sánchez ha dado lugar a interpretaciones muy variadas de su filosofía y cada una de estas interpretaciones ofrece una alternativa a su lectura.

En el año 1665, el teólogo alemán Gabriel Wedderkopf definió a Francisco Sánchez como "el restaurador del escepticismo en la edad moderna" (Senchet, 1904, p. 97). Aunque podríamos estar de acuerdo con esta afirmación, al menos en parte, sin embargo quizá deberíamos preguntarnos algo: ¿De qué tipo de escepticismo fue Francisco Sánchez el restaurador? ¿Su pensamiento presenta mayores puntos de contacto con el escepticismo pirrónico o con el académico? ¿Cuáles fueron las fuentes escépticas antiguas que leyó Sánchez y cómo influyeron en su concepción de la realidad y de la teoría del conocimiento?

Este tipo de preguntas no es nuevo. Consideraciones similares se originaron como consecuencia del modo de entender el escepticismo en los siglos XVI y XVII cuando, como puso de relieve el gran estudioso Charles B. Schmitt, la distinción entre el escepticismo pirrónico y el escepticismo académico no era del todo clara (Schmitt, 1972, pp. 5-9).

Como contraste evidente, Michel de Montaigne, en su Apología de Ramón Sabunde ${ }^{1}$ recogida en el libro II de sus Ensayos, cita directamente el párrafo con el que se abre el primer libro de las Hipotiposis pirrónicas de Sexto Empírico. El pensador francés delinea una distinción clara entre la involución dogmática del escepticismo (refiriéndose a las doctrinas de Arcesilao y Carnéades, representantes del que será conocido como escepticismo académico) y la genuina inspiración inquisitiva, siempre abierta la investigación y a la búsqueda, típica de la propuesta pirrónica (Montaigne, 2006; Bermúdez, 2007, p. 38).

Montaigne se muestra crítico con el aspecto constructivo del escepticismo académico. La idea de que haya representaciones más o menos probables y, por lo

1 La grafía de este nombre es compleja. En francés es Raimond Sebond, en catalán es Ramón Ribiuda y en español es Raimundo de Sabunde o Ramón de Sabunde. Fue un filósofo y teólogo español que trabajó como profesor de teología en Toulouse. 
tanto, que pueda haber grados de aproximación a la verdad, no tiene sentido en un sistema que ha declarado la intangibilidad de la verdad. A todo esto, Montaigne contrapone la coherencia de la epoché pirrónica, que demuestra ser "más audaz y también más razonable" (Montaigne, 2006, pp. 188-192).

La epoché pirrónica, entendida como suspensión del juicio, demuestra ser más razonable, puesto que si el escepticismo se propusiera como teoría escéptica correría el riesgo de caer en una flagrante contradicción. Sería algo así como la paradoja de la afirmación "no existen verdades absolutas". Los escépticos se dieron cuenta del riesgo que corrían, de ahí que describieran su propio posicionamiento filosófico no como una teoría, sino más bien como una postura de suspensión y de investigación.

El propio Montaigne no llegó a afirmar "no sé nada", sino que eligió como su lema principal el famoso “¿qué sé yo?”. Curiosamente, según Giulio Preti, esta afirmación no representa una posición filosóficamente válida (Preti, 1974, p. 5). Según este profesor italiano del siglo pasado, además de conocer varias verdades factuales que le afectan desde cerca, aquel que duda sabe con toda probabilidad que duda, y además conoce las razones que lo conducen a tal postura. No obstante, si una persona se pregunta “¿qué sé?”, eso significa que duda de la propia duda y de las razones para dudar, no logrando de este modo evitar la paradoja. No deja de resultar interesante esta objeción de Preti a la propia posición escéptica.

La distinción entre pirronismo y escepticismo académico está presente en otro gran filósofo del renacimiento: Giordano Bruno, lector de los escritos de Sexto Empírico y autor de dos obras en forma de diálogo en las que se discutían las doctrinas escépticas.

En La cena de las cenizas, obra de 1584, precisamente en la parte final del primer diálogo, donde Bruno expone las diferencias entre su modo de filosofar y otros modos de hacer filosofía, este hace decir a uno de los personajes, a Teófilo: "Otra costumbre tienen los efécticos y pirrónicos, los cuales, haciendo profesión de que no se puede saber cosa alguna, siempre van haciendo preguntas y buscando respuestas para no encontrarlas jamás” (Bruno, 1968, p. 71).

Evidentemente, en este caso "efécticos" y "pirrónicos" son términos que identifican al mismo tipo de escépticos (Román, 1994, p. 96). Según las indicaciones de Diógenes Laercio: 
Todos estos fueron llamados pirrónicos, tomando el nombre de su maestro y se distinguieron en aporéticos, escépticos, efécticos y zetéticos por sus principios, si es que resulta lícito hablar de principios. Se llaman efécticos o los que suspenden el juicio por el estado mental que sigue a la investigación (Diógenes Laercio, 2007, pp. 69-70; también Román, 1994).

En la Cábala del caballo Pegaso, libro de 1585, Giordano Bruno presenta algunas observaciones sobre los efécticos y los pirrónicos. En el primer diálogo, uno de los personajes, Saulino, afirma que para estos pensadores el conocimiento humano consiste en una suerte de ignorancia y los compara con un asno incapaz de elegir entre dos alternativas. Las similitudes con el famoso ejemplo del asno de Buridan son demasiado evidentes para tener que resaltarlas más. Saulino prosigue elogiando al escepticismo y afirma que el mejor conocimiento que se puede tener es aquel según el cual nada puede ser conocido. Este planteamiento es atribuido por Bruno a los socráticos, a los platónicos, a los efécticos y a los pirrónicos (Popkin, 2003, p. 36).

En el segundo diálogo, Saulino traza una distinción entre los efécticos y los pirrónicos. Los primeros son equiparados a los escépticos académicos, que son los que afirmaban que nada se puede conocer; los segundos, por el contrario, consideraban que ni siquiera se podría afirmar esto, que no se puede conocer nada (Popkin, 2003, p. 36).

En Pedro de Valencia, otro de los referentes del escepticismo del siglo XVI, volvemos a encontrar una falta de definición entre las diferentes posiciones escépticas (Bermúdez, 2006). A la división tripartita que establecen Sexto Empírico y Michel de Montaigne, se le suma otra división, en este caso bipartita, entre dogmáticos y escépticos, y a estos últimos se les reconoce la posibilidad de dar el propio asentimiento a las representaciones que dispongan de un mayor grado de probabilidad (Paganini, 1991, p. 22).

Existe un libro particularmente interesante para discutir estos temas sobre las fuentes escépticas en el Renacimiento y que no ha recibido la atención que quizá merecería. Se trata de La verité des sciences. Contre les Sceptiques ous Pyrrhoniens, del padre Mersenne. Aquí, el autor presenta un diálogo entre un alquimista, un escéptico y un filósofo cristiano, utilizando las herramientas de la panoplia escéptica para encauzar una severa crítica anti-dogmática. Esta crítica contra los postulados dogmáticos es utilizada, curiosamente, para llegar a delinear 
una aproximación cognoscitiva posterior basada sobre la nueva ciencia mecanicista (Paganini, 1991, p. 73).

Vale la pena señalar que, en este caso, se hace coincidir el pirronismo, ya en el propio título de la obra, con el escepticismo en su conjunto. En 1665 Pascal, en su Entretien avec M. de Sacy, también hablaba de la duda pirrónica y de la duda académica sin hacer ningún tipo de distinción entre estas dos actitudes escépticas (Limbrick, 1988, p. 68).

La diferencia fundamental entre ambas posturas escépticas es puesta de manifiesto por Pierre Bayle en su Dictionnaire Histórique et Critique, concretamente en el artículo que escribió sobre Pirrón (Bayle, 1702, tomo III; pp. 731-736). Bayle, además de ser el responsable del apelativo de "el escéptico" que acompañó a Francisco Sánchez durante mucho tiempo, en un primer momento, concretamente en el desarrollo del artículo sobre Pirrón, escribe: "Entre las opiniones de Pirrón y la de Arcesilao no había prácticamente ninguna diferencia, dado que tanto el primero como el segundo enseñaban la incomprensibilidad de todas las cosas" (Bayle, p. 731; la traducción es nuestra). Si juzgáramos la posición de Bayle por este fragmento, evidentemente tendríamos que concluir que el pensador francés no encontraba diferencias reales entre escepticismo pirrónico y escepticismo académico. No obstante, en las notas del artículo, que son, probablemente, incluso más importantes que el contenido propio del artículo de su diccionario, Bayle consigna una precisión que se torna de capital importancia para nuestra comprensión de su opinión sobre los diversos tipos de escepticismo:

Sin embargo, he preferido dejar entre los dos alguna diferencia, ya que los pirrónicos no suponen formalmente ni siquiera la incomprensibilidad de la realidad. Han sido llamados escépticos, zetéticos, efécticos y aporéticos, esto es, los que buscan, los que investigan las cosas, los que suspenden el asentimiento y los que dudan. Todas estas expresiones vienen a demostrar que, según ellos, era posible encontrar la verdad y que no afirmaban la incomprensibilidad" (Bayle, 1702, p. 733; la traducción es nuestra).

El pensador francés continúa en las notas del artículo por esta senda. Citando a Aulo Gelio (Noches Áticas, XI, 5), Bayle escribe:

Aunque pirrónicos y académicos dicen de modo similar tales cosas, difieren entre sí, sin embargo, a causa de otras, y quizá son juzgados sobre todo porque los académicos por lo menos dicen que nada puede ser comprendido, como si comprendieran y que nada puede ser discernido, como si discernieran. En 
cambio, los pirrónicos dicen que ni siquiera parece en absoluto verdad que nada parezca verdad (Bayle, 1702, p. 733).

A la objeción de Aulo Gelio que recoge Bayle, este agrega otra más:

Sexto Empírico encontró otra diferencia: Arcesilao pretendía que por naturaleza la suspensión del juicio era buena y la afirmación mala; en cambio, según Pirrón, no lo eran más que en apariencia: "non secundum naturam, sed secundum id quod apparet". En el fondo, ambos mostraban el mismo ardor en defender la duda, y nada era más fácil que ponerlos de acuerdo. No había más que pedirles que se explicaran clara y sinceramente (Bayle, 1702, p. 734).

El escepticismo pirrónico fue considerado una doctrina extremadamente atrayente para muchos intelectuales. El siglo XVII fue un periodo de una reflexión intensa sobre las consecuencias del pirronismo que habían sido señaladas por la Apología de Ramón Sabunde de Montaigne. Así ocurrió, por ejemplo, con los jansenistas de Port Royal, como señala Elaine Limbrick en su edición del Quod nihil scitur (Limbrick, 1988, p. 68). De este modo, no tiene que sorprendernos que el discípulo dilecto de Francisco Sánchez, Delassus, en la biografía que escribió de su maestro como prefacio de la edición de la Opera medica, afirmara que Sánchez seguía la suspensión del juicio pirrónica. Desde el punto de la investigadora británica, esta opinión de Delassus estaba completamente equivocada.

Sin embargo, probablemente basándose en este escrito, Pierre Bayle terminó por formular el mismo juicio y definió a Francisco Sánchez como "un gran pirrónico", como también recoge Limbrick (1988, p. 68). Y es aquí donde nos surge uno de los primeros puntos de fricción sobre este asunto de la clasificación escéptica del autor del Que nada se sabe. La afirmación de Delassus que situaba a su maestro del lado del escepticismo pirrónico tiene gran importancia para nuestro análisis. No se puede desdeñar un testimonio así, sobre todo partiendo de la premisa de que fue un hombre que tuvo contacto directo con Sánchez y que fue su discípulo. Aquellos que, como Elaine Limbrick, pretendan distanciar al filósofo tudense de las fuentes pirrónicas no deben pasar por alto la categorización de Delassus. Para la investigadora británica Elaine Limbrick, ni en las obras filosóficas ni en las obras médicas de Francisco Sánchez existía indicio alguno de su adhesión al escepticismo pirrónico (Limbrick, 1988, p. 69). El examen de los argumentos escépticos utilizados en el Que nada se sabe no aporta ninguna prueba de que el autor haya leído o las Hipotiposis pirrónicas o 
Contra los profesores. Así, por descarte, Sánchez habría entrado en contacto con los principios fundamentales del escepticismo a través de la lectura de las obras de Galeno, Diógenes Laercio, Plutarco, Cicerón y San Agustín.

Sin embargo, conviene presentar un contraargumento que no es baladí. Erasmo de Rotterdam tradujo la obra de Galeno, De optimo docendi genere, en 1526. Esta obra fue insertada en la edición de 1569 de las obras de Sexto Empírico llevada a cabo por Gentian Hervet. Hervet, un contrarreformista francés que fue secretario del cardenal de Lorena y participó en el Concilio de Trento, editó las obras de Sexto Empírico en 1569 incluyendo la edición de 1562 de Henri Estienne (esta última fue la primera edición de las obras de Sexto Empírico). Sánchez, en su Que nada sabe, que ya sabemos que fue publicado en 1581 pero escrito en 1574 (Bermúdez, 2006, p. 219), cita la obra de Galeno, el De optimo docendi genere. Este sería el único indicio a favor de una lectura directa de los escritos de Sexto Empírico por parte del filósofo de Tuy. Pero es un indicio fuerte.

Frente a Limbrick, Richard Popkin, a la luz de la interpretación global del resurgimiento del escepticismo en el Renacimiento y con una visión más general, defendió la deuda que el pensamiento de Francisco Sánchez tenía con el escepticismo de Sexto Empírico (obviamente, deuda que se suma a las más evidentes que se tenían contraídas con Cicerón y Diógenes Laercio) (Popkin, p. 42). Popkin se sumaba así, con esta idea, a las posturas de Carvalho y de Senchet.

Según Joaquim de Carvalho, ya fuera el estilo, ya fueran algunos de los argumentos del Que nada se sabe de Sánchez, ambos parecían derivar de la traducción de Sexto Empírico que llevó a cabo Henri Stienne en 1562 (Carvalho, 1981, p. 530). Emilien Senchet, por otra parte, comparó las argumentaciones contenidas en el Que nada se sabe con las de Sexto Empírico y llegó a definir a Sánchez como "el continuador de Sexto" (Senchet, 1904, p. 72).

Nosotros hemos defendido en otra parte (Bermúdez, 2006, pp. 23 y ss.) que expresiones como methodus sciendi fueron forjadas en las fraguas del escepticismo. Senchet sugirió que la idea de Sánchez de renovar el método científico le había venido de la lectura de Sexto Empírico y de Galeno (no olvidemos que ambos autores aparecen en la edición completa de las obras de Sexto de 1569). A pesar de entrever un diferencia de fondo entre el planteamiento de Sexto y la del autor del Que nada se sabe (por ejemplo, en el hecho de que Sánchez se detiene antes que Sexto en la vía de la duda, sobre todo al admitir que la experiencia sensible 
y el juicio, si van unidos, pueden permitirnos cierta aproximación aunque remota a la verdad o, al menos, una forma de conocimiento útil para la acción humana), Senchet destaca sobre todo las coincidencias que hay entre los dos filósofos, como, por ejemplo, el rechazo de la metafísica y de la lógica formal.

Senchet reconoce una influencia decisiva de Sexto sobre Sánchez allí donde el gallego habla de los obstáculos que se oponen a la consecución del conocimiento y examina el objeto, el ambiente externo y el sujeto (el espíritu y los sentidos). El investigador francés, además, encuentra en el Que nada se sabe los modos de la epoche, la suspensión del juicio, presentados en las Hipotiposis pirrónicas, si bien dispuestos en un orden distinto (Senchet, 1904, p. 81). Asimismo, Senchet también recoge otras teorías que hacen de Sánchez el heredero y continuador de ilustres personajes como Nicolás de Cusa y Ramón Sabunde, cuyas obras habían sido publicadas poco antes de la edición de su libro (Senchet, 1904, p. 2).

Otra autoridad que se suma a esta corriente es Pierre Villey. El autor de Les sources et l'évolution des Essais de Montaigne considera que uno de los elementos comunes entre el escepticismo de Sánchez y el escepticismo de Montaigne se puede localizar en la influencia masiva que el pirronismo ejerció sobre las obras de Sexto Empirico (Villey, 1968, pp. 166 y ss.). Esta también es la opinión de Andrée Comparot, que reconoce un paralelismo entre la concepción fideística expresada en algunos pasajes del Que nada se sabe y el prefacio de Gentian Hervet a su traducción latina del Contra los profesores de Sexto Empírico. Esta estudiosa francesa, Comparot, señala también una coincidencia nada desdeñable para el asunto que aquí nos ocupa. Parece ser que Gentian Hervet fue maestro en el colegio de Guyenne en un periodo que, tal vez, pudo coincidir con la estancia que Sánchez pasó allí como estudiante (Comparot, 1984, p. 29).

Decíamos antes que el investigador francés Emilien Senchet había hecho de Sánchez un heredero intelectual de Nicolás de Cusa y de Ramón Sabunde. Este último, como Sánchez, también había trabajado en Toulouse y con su influencia pudo hacer ver al pensador de Tuy la posibilidad de conciliar la fe cristiana con la duda; el pensador catalán, Ramón Sabunde, además, hace hincapié sobre el papel de la experiencia en el proceso cognoscitivo y, en particular, en la práctica médica (no debemos olvidar que Sabunde, como Sánchez, fue uno de los miembros más ilustres de la facultad de medicina de la Universidad de Toulouse). 
En virtud de todo lo antedicho, el rechazo de la metafísica y la lógica aristotélicas, la polémica contra la abstracción y la esterilidad de las ciencias matemáticas, Senchet vincula la postura filosófica de Sánchez con la doctrina de la "docta ignorancia" de Nicolás de Cusa, cuyas obras habían sido reeditadas en 1565 en Basilea (Bermúdez, 2006, pp. 32-33).

En su De docta ignorantia, Nicolás de Cusa desarrolla un discurso sobre la naturaleza y sobre los límites del conocimiento humano, sacando a la luz cómo este suele proceder a través de definiciones y comparaciones. Conocer es comparar objetos limitados que son homogéneos entre ellos, reconduciendo lo ignorado hacia lo conocido a través de clasificaciones generales. Así, el conocimiento se limita a aquello que es finito, pues la razón está hecha solo para conocer lo mensurable. De ahí que la razón tenga que declararse incapaz de conocer a Dios, ya que no se le puede comparar con ninguna otra cosa. Solo se podría conocer lo infinito si hubiera alguna proporcionalidad entre las cosas y Dios, pero no la hay, ya que no se pueden establecer semejanzas entre lo finito y lo infinito. De aquí que el cusano, en su adscripción neoplatónica, critique la forma en que la lógica aristotélicoescolástica estaba implantada, en la cual el objeto quedaba reducido y definido por unas categorías dadas. Solo una visión intuitiva puede recoger lo absoluto y ello teniendo muy en cuenta que será sin comprenderlo en su justa medida. El saber más alto consistirá, por lo tanto, en la conciencia de los límites del conocimiento discursivo y en la comprensión de que el camino hacia lo absoluto es un proceso continuo inagotable (Cusa, 1966, pp. 57-66).

La crítica de la lógica aristotélica, acusada de ser incapaz de captar la verdad, constituye sin duda un elemento común tanto a Sánchez como al cusano. Por consiguiente, ambos se emplearon en la búsqueda de un método que fuera capaz de hacer progresar la razón humana hacia un tipo de conocimiento más estable y útil, aunque fuera imperfecto. De hecho, en Nicolás de Cusa encontramos la idea de que se puede conocer verdaderamente solo aquello que hemos creado, hecho del cual se deriva la distinción entre conocimiento imperfecto y conocimiento perfecto, siendo este último prerrogativa exclusiva de Dios. De este modo, el camino hacia la verdad se revela, desde este punto de vista, como un proceso continuo sin posibilidad de conclusión (Sánchez, 1984, p. 89). Senchet insiste en que la relación entre el pensamiento del cusano y el de Sánchez es muy estrecha. En su opinión, Sánchez tuvo que ser uno de los que leyeron la nueva edición de las obras de Nicolás de Cusa (Senchet, 1904, p. 37). 
Otro pensador que influyó en el Que nada se sabe es el español Luis Vives. Algunos pasajes de la obra de Sánchez revelan una influencia evidente del De disciplinis del humanista español. Vives había criticado la oscuridad de Aristóteles y de sus comentadores, así como el formalismo de los escolásticos y su abuso de los sofismas (Rodríguez Peregrina, 1995, pp. 418-420). La primera parte del De disciplinis, que lleva por título De causis corruptarum artium, exponía las causas de la decadencia del lenguaje, de la ética y de la filosofía natural. A pesar de su crítica a Aristóteles, Vives reconoce la gran profundidad de su análisis y su espíritu, palabras que Sánchez también utilizó en su libro para referirse al estagirita (Limbrick, 1988, p. 30).

Vives, al mismo tiempo que condenaba la postura aristotélico-escolástica y el modo de estudiar y de enseñar filosofía que llevaba conectada, recurría a una teoría del conocimiento en la que las doctrinas neo-académicas se unían a una concepción según la cual la única forma verdadera de conocimiento es la divina. De modo tal que la posición escéptica tenía una función de "moderadora". La postura escéptica tenía la obligación de señalar los límites de la razón humana y, por contraste, del conocimiento perfecto que Dios tiene de las cosas al haberlas creado. En este mismo sentido se pronunció Sánchez en su Que nada se sabe (Sánchez, 1984, p. 132). Pero aunque esto no fuera suficientemente evidente, también podemos agregar otra cuestión. La doctrina escéptica de la probabilidad, contenida en dos de los libros del De disciplinis (en De instrumento probabilitatis y en De censura veri et falsi), constituye claramente una de las fuentes de la postura escéptica de Sánchez sobre el problema del método científico.

De hecho, Vives afrontó la cuestión y teorizó un método de conocimiento, como después hará Sánchez. El método de Vives estaba concebido como procedente de las sensaciones al juicio, de aquello que era inferior a lo que era superior. Por un lado, las experiencias, dirigidas por la razón, pierden su carácter fragmentario y casual; por otro lado, el pensamiento, basándose en esas experiencias, descubre nuevas perspectivas, se eleva a la idea general susceptible de nuevas aplicaciones (Senchet, 1904, p. 17).

Senchet ha reconocido en esto el "principio de acuerdo entre pensamiento y realidad" (Senchet, 1904, p. 14), que es el principal punto de contacto entre los dos pensadores. Como Sánchez, Vives puso de manifiesto la importancia de la experiencia sensible como base del proceso cognoscitivo, y el papel de la razón 
("lumen naturale") en la dirección y organización de las observaciones empíricas (Limbrick, 1988, p. 32).

Vives, en su obra De instrumento probabilitatis, afirma que hay tres instrumentos cognoscitivos diversos: los sentidos, la autoridad y la razón que tiene como base la experiencia (Limbrick, 1988, p. 31). Solo esta última es fiable y permite al hombre aproximarse a la verdad. De ahí que Vives elogie el arte de la medicina, que se basa en la observación empírica y en el juicio, reivindicando, como hará Sánchez, la concepción similar de Galeno desarrollada por este en su De medendi metodo (Limbrick, 1988, p. 33).

Según Senchet, el punto de partida común entre Vives y Sánchez estaría constituido por el fenomenismo (Senchet, 1904, p. 18): ambos se opusieron a las especulaciones de los escolásticos, proponiendo un tipo de ciencia más limitada, sí, pero también más fecunda porque estaría sometida al control de la experiencia.

Con Sánchez, la crítica del dogmatismo se afirmó de una manera más profunda y decisiva y los límites del conocimiento humano se vieron redimensionados. Vives, de hecho, a pesar de haber criticado el abuso de los silogismos en el Adversus pseudodialecticos, obra de 1520, en su libro De censura veri et falsi, define el silogismo formal como una argumentación perfecta (Limbrick, 1988, p. 32), reevaluando de este modo el alcance cognoscitivo que podrían presentar. Esta situación, junto con el interés demostrado por Vives en el aspecto retórico de la lógica, constituye sin duda un punto de separación entre Vives y Sánchez.

No obstante, Sánchez y Vives sí que compartieron la misma posición frente a la matemática. Como Sánchez, también Vives pone en duda la certeza, al considerarla como meramente basada en principios de orden puramente conjetural y clasificándola como una actividad completamente improductiva y estéril (Limbrick, 1988, p. 34). Es digno de señalar el hecho de que Vives, para apoyar sus propias argumentaciones, citara a Cicerón y a Séneca como filósofos que habían puesto en duda las bases teóricas de la geometría.

En conclusión, aunque sigue sin haber acuerdo entre los investigadores sobre las fuentes que influyeron en Francisco Sánchez a la hora de escribir su obra Que nada se sabe, parece evidente que hay una serie de autores cuya impronta se percibe tras la lectura de las páginas del tudense. Entre estos estarían Galeno, Diógenes Laercio, Plutarco, Cicerón, San Agustín y Luis Vives, sobre los que ha 
habido más o menos consenso. Pero sería demasiado imprudente por nuestra parte negar la existencia de una probabilidad más que elevada que indica que, entre las fuentes que conocía Sánchez se encontraba la obra de Sexto Empírico.

\section{Referencias}

Bayle, P. (1702). Dictionnaire Historique et Critique. Rotterdam: Editorial Reinier Leers.

Bermúdez Vázquez, M. (2006). La recuperación del escepticismo en el Renacimiento como propedéutica de la filosofía de Francisco Sánchez. Madrid: Fundación Universitaria Española.

Bermúdez Vázquez, M. (2007). Michel de Montaigne: La culminación del escepticismo en el Renacimiento. Córdoba: Servicio de Publicaciones de la Universidad de Córdoba.

Bermúdez Vázquez, M. (2014). La fuerza de la duda: Francisco Sánchez el escéptico. Madrid: Dionysianum.

Bermúdez Vázquez, M. (2016). Pedro de Valencia. Disponible en: http://www.uco.es/ philosophical-skepticism/philosophical-skepticism/reception-and-survival/pedro-valencia. html

Bruno, G. (1968). Giordano Bruno e Tomasso Campanella (L. Firpo, Ed.). Scritti scelti. Torino: Utet.

Carvalho, J. de (1981). Obra completa. I/2, Filosofia e historia da filosofía. Lisboa: Fundaçao Calouste Gulbenkian.

Comparot, A. (1984). Il n'est science de rien. Edición crítica latín-francés. Paris: Klincksieck. Cusa, N. de (1966). La docta ignorancia (Manuel Fuentes Benot, Trad.). Buenos Aires: Aguilar. Diógenes Laercio. (2007). Vidas de filósofos ilustres. Madrid: Alianza Editorial.

Limbrick, E. (1988). That nothing is known (Quod nihil scitur). Introducción, nota y bibliografía de Elaine Limbrick. Cambridge: Cambridge University Press.

Montaigne, M. de (2006). Ensayos. Barcelona: Acantilado.

Paganini, G. (1991). Scepsi moderna. Interpretazioni dello scetticismo da Charron a Hume. Cosenza: Busento.

Popkin, R. (2003). The History of Scepticism from Savonarola to Bayle. New York: Oxford University Press.

Preti, G. (1974). Lo scetticismo e il problema della conoscenza. Rivista critica di storia della filosofia, 29(2), 123-143.

Rodríguez Peregrina, J. M. (1995). La retórica clásica en el De disciplinis de Luis Vives. Florentia Iliberritana. Revista de estudios de Antigüedad Clásica, 6, 417-431.

Román, R. (1994). El escepticismo antiguo: posibilidad del conocimiento y búsqueda de la felicidad. Córdoba: Servicios de Publicaciones de la Universidad de Córdoba.

Sánchez, F. (1984). Quod nihil scitur. (Sergio Rábade, J. M. Artola y M. F. Pérez, Trad.). Madrid: Consejo Superior de Investigaciones Científicas. 
El problema de las fuentes escépticas en el Renacimiento: el caso del Quod nihil scitur...

Sánchez, F. (1988). That nothing is known (Quod nihil scitur). Introducción, nota y bibliografía de Elaine Limbrick. Cambridge: Cambridge University Press.

Schmitt, Ch. B. (1972). Cicero scepticus. La Haye: Martinus Nijhoff.

Senchet, E. (1904). Essai sur la méthode de Francisco Sanchez. Paris: V. Giard \& E. Briére.

Villey, P. (1968). Les sources et l'évolution des Essais de Montaigne. New York: Burt Franklin. 